\title{
EVALUATION OF GAS METAL ARC WELDING WITH ALTERNATING SHIELDING GASES FOR USE ON AA6082T6
}

\author{
S.W.Campbell ${ }^{1}$, A.M.Galloway ${ }^{1}$, N.A.McPherson ${ }^{2}$ and A.Gillies ${ }^{3}$ \\ ${ }^{1}$ Department of Mechanical \& Aerospace Engineering, University of Strathclyde, Glasgow \\ ${ }^{2}$ BAE Systems Surface Ships Limited,1048 Govan Road, Glasgow \\ ${ }^{3}$ Weir Oil \& Gas, Bramah Avenue, East Kilbride, Glasgow
}

\begin{abstract}
Studies have been carried out to determine the effects of implementing alternating shielding gases for $6082 \mathrm{~T} 6$ aluminium alloy welding. Alternating shielding gases is a newly developed method of supplying shielding gases to the weld area to enhance the efficiency of the standard Gas Metal Arc Welding (GMAW) process.
\end{abstract}

This method involves discretely supplying two different shielding gases to the weld zone at a pre-determined frequency which creates a dynamic action in the weld pool. Several benefits have been identified in relation to supplying shielding gases in this manner including increased travel speed, reduced distortion, reduced porosity and, in the case of specific alternating frequencies, marginal improvements in mechanical properties. All in all, this method of shielding gas delivery presents attractive benefits to the manufacturing community, namely the increased productivity and quality in addition to a reduction in the amount of post-weld straightening required.

However, the literature available on this advanced joining process is very scant, especially so for aluminium alloys. For this reason, an evaluation has been carried out on the application of alternating shielding gases for the GMAW process on 6082T6 aluminium alloys. 


\section{Introduction}

Initially developed in the 1920s, GMAW is a fusion joining process in which an arc is established between a continuously fed filler wire electrode and the workpiece.

Shielding gases are fundamental to most welding processes; their primary purpose being to protect the molten weld pool from contamination by atmospheric gases. In addition, computational models have shown that the shielding gas implemented in the GMAW process can be selected to tailor the weld to meet a desired specification [1]. There are a number of shielding gases commonly used, each with its own specific properties [1-9], which can have pronounced affects on the arc characteristics, mode of metal transfer, cleaning action, penetration level and weld shape. Consequently, the shielding gas can also have a positive influence on the travel speed as reported by Gillies et al. [9]

The shielding gas used is selected depending upon the material to be welded. There are two commonly used gases employed for the welding of aluminium, argon and helium. Shielding gases are also commonly utilised in a variety of premixed combinations in order to take advantage of the beneficial properties of each gas $[10,11]$

It is widely recognised that additions of helium to a shielding gas combination can have beneficial effects on increasing the penetration depth of a weld. Jönsson et al. [12] reported on the effects that either argon and helium have on the temperature distribution within the arc column. They concluded that helium produces a narrower temperature distribution and higher temperature at the surface of the workpiece, as shown in Figure 1 [12], resulting in a more contracted weld bead with greater penetration. This is a consequence of helium having a higher first ionisation potential 
than argon, this results in helium having a higher arc power density and therefore produces a more constricted cathode spot generating greater penetration. However, due to the high unit cost of helium, it is only normally implemented in thicker sections.

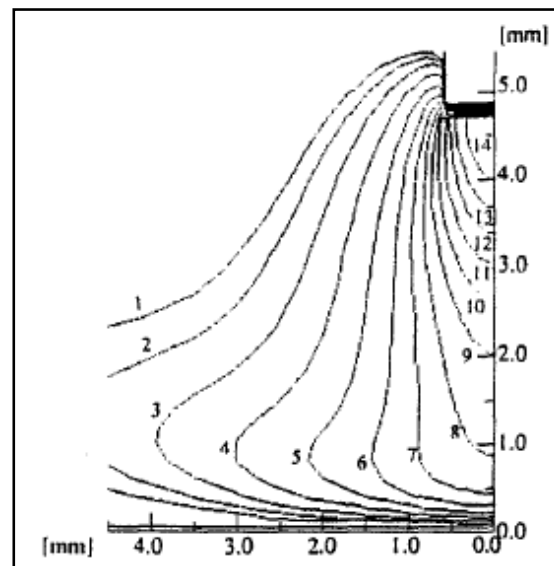

(a)

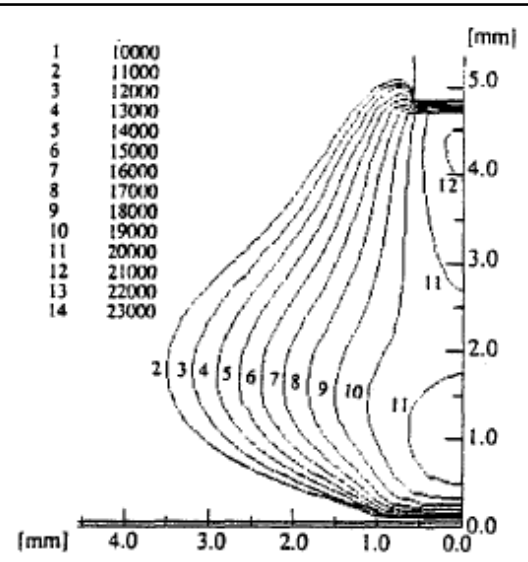

(b)

Figure 1: Temperature Contours for (a) Argon and (b) Helium at a 200 A Welding Current [12]

Several industries [13] are moving towards thinner, lighter and stronger materials (such as AA6082T6) to reduce the overall mass of the structure and with the aim of improving efficiency. For example, the transportation industries are continually striving to increase fuel efficiency as a consequence of increasing oil prices and the introduction of legislation governing exhaust emissions. It has been reported that a $10 \%$ reduction in weight corresponds to a $5.5 \%$ reduction in fuel consumption, with each $\mathrm{kg}$ saving said to equate to a $20 \mathrm{~kg}$ reduction in $\mathrm{CO}_{2}$ emissions over a 170000 $\mathrm{km}$ lifetime, and since the density of aluminium is approximately $1 / 3$ that of steel, there is considerable scope for improvement. Aluminium alloys also have a use in the shipping industry where its use allows for a smaller portion of the ship to be beneath water level allowing for a greater number of passenger decks. Aluminium alloys are also used higher up the naval structure in order to enhance structure stability. Al-Cu-Mg (2xxx series) alloys are used extensively in the aerospace sector, 
however movements are being made towards $6 \mathrm{xxx}$ series alloys due to benefits associated with improved weldability and cost, with the added benefit of weight saving as a consequence of not requiring cladding to prevent corrosion.

However, it is widely acknowledged that, during welding, thinner aluminium alloy plates are also more susceptible to heat induced distortion due to their lower stiffness. Distortion is the result of the non-uniform expansion and contraction of the weld material due to the heating and cooling cycle [14] and with a higher thermal expansion coefficient, aluminium alloy structures are more susceptible to distortion than steel structures. Computational models have been developed to help predict distortion [15-17]; in spite of this, as a result of distortion being closely related to the weld heat input, it is of paramount importance to eradicate as much heat input as possible in order to mitigate the final distortion level. Post-weld fabrication techniques such as flame straightening are commonly used to remove distortion from the structure; nevertheless, this method is highly resource intensive, does not add value to the final product and potentially degrades the material properties in the heated region. Therefore, reducing the initial distortion is of economic and practical importance. Other methods of reducing the induced distortion include friction stir welding and thermal tensioning; this method utilises additional heat, on specific areas of the structure, with the aim of altering the residual stresses present within the structure.

Recently, there has been positive research into the effects of implementing alternating shielding gases [1-5]. This method involves discretely supplying two different shielding gases to the weld pool in order to take advantage of the beneficial properties of each gas. Chang [3] reported that argon and helium produce weld pool flow vectors opposite in direction, as shown in Figure 2 [4]. This technique of 
alternating shielding gases has been reported to produce an additional preferential effect within the weld pool in the form of a dynamic action caused by complex flow patterns generated when fluctuating between shielding gases. Chang [3] reported that this dynamic action is a result of three independent phenomena: arc pressure variation, variation of weld pool fluidity and arc pressure peaking. These phenomena combine to produce a stirring action within the weld pool, which, coupled with the increased pool fluidity when welding with helium help gas pores escape thus reducing porosity.

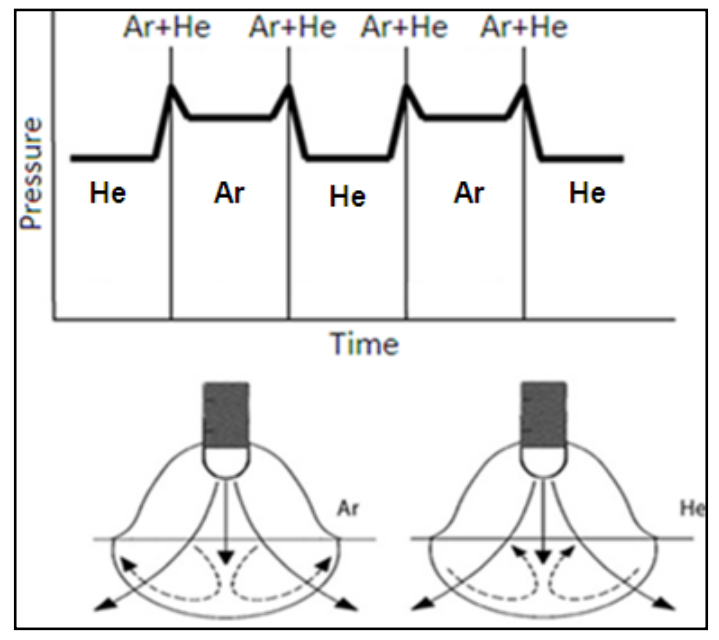

Figure 2: Arc Pressure and Fluid Flow Vectors [4]

A reduction in heat input can be achieved by increasing the speed of travel, although this is only an option if not adversely affecting the mechanical properties of the welded joint. Initial studies [2] have shown beneficial results including increased travel speed, reduced porosity and improved mechanical properties in a steel structure. Campbell et al. [2] reported that the use of alternating shielding gases can considerably reduce distortion in thin plate $\mathrm{DH} 36$ steel as a result of reducing the heat input due to increasing the speed of travel, this has also given rise to a reduction of $17 \%$ in overall weld costs. It has also been shown, via the aid of computational models, that the application of alternating shielding gases permits an 
increase in travel speeds whilst generating welds meeting specified geometry requirements and quality [1].

Shielding gases are used to protect the weld pool from contamination, however, due to a variety of reasons including inadequate shielding gas flow, excessive shielding gas flow, cross drafts and damaged welding apparatus, insufficient protection of the weld pool is provided. Porosity formation in aluminium occurs due to hydrogen being drawn into the electric arc and is a serious issue with respect to this material. Hydrogen is dissociated, absorbed into, and spread throughout the weld pool. During solidification of the weld pool, hydrogen gas bubbles form, some of which are able to escape from the pool due to buoyancy effects. However, gaseous hydrogen that does not escape when the weld pool solidifies creates voids in the solid weld metal. As a result of hydrogen having a higher solubility in molten aluminium and very low solubility in solid aluminium, there is potential for excessive amounts of porosity to be present in the final weld. The dynamic action reported by Chang [3] assists with the buoyancy effect in removing these hydrogen bubbles thus reducing weld porosity.

Min et al. [18] reported that the weld heat input affects the recrystallisation of the heat affected zone (HAZ) in magnesium alloys with an increase of less than $50 \%$ resulting in grains more than double the original grain size. In contrast, Campbell et al. [2] showed that a finer grain structure was produced in DH36 steel when implementing the use of alternating shielding gases and a lower heat input. Their work [2] also showed that a finer homogeneous grain structure consequently resulted in more uniform material properties throughout. This is to be expected, as a finer grain structure results in a higher density of grain boundary interactions and therefore requires more energy to allow a dislocation to propagate. It follows that the yield strength is related to the grain size through the Hall-Petch equation, Equation 1. 


$$
\sigma_{y}=\sigma_{1}+k_{y} d^{-1 / 2}
$$

Where: $\quad \sigma_{y} \quad$ - yield strength

$$
\begin{aligned}
& \text { d } \quad \text { - average grain diameter } \\
& \sigma_{1}, k_{y} \text { - material specific constants }
\end{aligned}
$$

\section{Experimental Set-up}

In the present study, a series of welding trials were performed on $6082 T 6$ aluminium with a typical chemical composition shown in Table 1. Trials were performed on 6 $\mathrm{mm}$ thick $6082 \mathrm{~T} 6$ aluminium in the form of $125 \times 250 \mathrm{~mm}$ plates with a $30^{\circ}$ angle machined whilst leaving a $1.5 \mathrm{~mm}$ root face with a ceramic backing strip applied to the underside of the weldment. The average welding parameters can be seen in Table 2.

\begin{tabular}{|c|c|c|}
\hline & \multicolumn{2}{|c|}{ Chemical Composition (wt. \%) } \\
\hline & Minimum & Maximum \\
\hline Silicon & 0.70 & 1.30 \\
\hline Manganese & 0.40 & 1.00 \\
\hline Copper & & 0.10 \\
\hline Titanium & & 0.10 \\
\hline Zinc & & 0.20 \\
\hline Magnesium & 0.60 & 1.20 \\
\hline Iron & & 0.50 \\
\hline Chromium & & 0.25 \\
\hline Aluminium & Balance & Balance \\
\hline
\end{tabular}

Table 1: AA6082T6 Chemical Composition

\begin{tabular}{|c|c|c|c|}
\hline Shielding Gas Configuration & Voltage $(\mathrm{V})$ & Current $(\mathrm{A})$ & Travel Speed $(\mathrm{mm} / \mathrm{s})$ \\
\hline Constant Argon & 20.7 & 129 & 6.2 \\
\hline Alternating @ 2.5 Hz & 20.7 & 121 & 6.7 \\
\hline Alternating @ 5 Hz & 20.7 & 121 & 6.9 \\
\hline Alternating @ 7.5 Hz & 20.7 & 125 & 7.1 \\
\hline
\end{tabular}


Two separate shielding gases were used throughout this experimentation, argon and helium, each with a constant flowrate of $15 \mathrm{l} / \mathrm{min}$. The base case was constant argon which allowed a direct comparison for the alternating cases.

The alternating frequency of the shielding gases was controlled through the use of a dedicated electronic control unit. The basis of which being two 555 timing circuits, which, set in 'astable' mode produces a continuous square wave at a specified frequency. The output from the two circuits then controlled the current supply to two solenoid valves in order to regulate the flow of each gas. An oscilloscope was then implemented to validate the output of the unit.

The unit used to control the flow of gases is an experimental unit that is not currently commercially available. The unit is a simple set-up which was minimal in cost to generate, nonetheless, any modest capital investment is likely to be substantially outweighed by the potential savings and benefits identified.

The filler wire used throughout was $1.2 \mathrm{~mm}$ diameter Alumig Si5 4043 aluminium wire with the typical chemical composition shown in Table 3.

\begin{tabular}{|c|c|c|c|}
\hline & \multicolumn{3}{|c|}{ Chemical Composition (wt. \%) } \\
\hline & Minimum & Typical & Maximum \\
\hline Silicon & 4.50 & 5.00 & 5.50 \\
\hline Manganese & & 0.01 & 0.05 \\
\hline Copper & & 0.03 & 0.05 \\
\hline Titanium & & 0.01 & 0.15 \\
\hline Zinc & & 0.01 & 0.1 \\
\hline Magnesium & & 0.01 & 0.05 \\
\hline Iron & & 0.20 & 0.40 \\
\hline Aluminium & & Balance & Balance \\
\hline \multicolumn{4}{|c}{ Table 3: Filler Wire Chemical Composition } \\
\end{tabular}

All welds were performed on an automatic welding rig, which held the plate rigid whilst moving at a preset speed under a fixed welding torch. The rig also allowed for distortion measurements to be taken through the use of an optical distance sensor 
which scanned the workpiece according to a pre-determined grid pattern before welding and after a cooling period, the difference between the two scans being the weld induced distortion. The plates were positioned upon four corner locating points, each of which were calibrated using the optical sensor to result in zero deformation at these locations.

Thermal data for each weld was captured using both a thermal imaging camera and K-type thermocouples at the mid-point of the plates, between 10 and $80 \mathrm{~mm}$ from the weld centreline in $10 \mathrm{~mm}$ increments. It was assumed that the temperature distribution within the plates was symmetrical, hence, readings were captured from one side of the weld. The thermal imaging camera was positioned directly above the weldment and analysed using the ThermaCAM Researcher programme, this confirmed the symmetry assumption.

A pre-calibrated, portable arc monitoring system (PAMS) unit was used throughout experimentation to accurately obtain the welding arc voltage and current. The sample frequency of $5 \mathrm{kHz}$ allowed for an accurate representation of the welding parameters and permitted a clear understanding of how the gas configuration affected these parameters.

Prior to welding, the workpieces were coated with low emmisivity paint $(\cong 1)$ to ensure accurate data collection by the thermal imaging camera.

Using the data obtained from the PAMS unit and ignoring the effects of a thermal efficiency factor, the average heat input (Q) was calculated for each shielding gas using Equation 2, as shown in Table 4.

$$
Q=\frac{\text { Voltage } * \text { Current }}{\text { Travel Speed }}(\mathrm{J} / \mathrm{mm})
$$




\begin{tabular}{|c|c|}
\hline Shielding Gas Configuration & Heat Input (J/mm) \\
\hline Constant Argon & 430.7 \\
\hline Alternating @ 2.5 Hz & 373.8 \\
\hline Alternating @ 5 Hz & 363.0 \\
\hline Alternating @ 7.5 Hz & 364.4 \\
\hline \multicolumn{2}{|c|}{ Table 4: Heat Input } \\
\hline
\end{tabular}

The heat input is an important consideration given its relationship with induced distortion. The heat input for the alternating cases is greatly reduced as an outcome of the reduced voltage and current. The level of heat input is not only of paramount importance to the induced distortion but it also affects the recrystallisation rate of the HAZ $[2,18]$ and can therefore have detrimental effects on the mechanical properties of the weld area.

\section{Results and Discussion}

\section{Distortion}

Distortion poses major problems in industry since many lightweight structures are constructed by the assembly of sub structures of increasingly stringent tolerances. Therefore, limitation of distortion is desirable in the final product to ensure accurate fit-up. For this reason, manufacturing companies strive to reduce the level of distortion at source and thus reduce the rework required to ensure assemblies fit together. This is largely achieved through good welding practices primarily related to reducing the weld heat input and the application of heat in specific areas.

In the present study, the material deformed in a classical saddle like shape due to the longitudinal and transverse shrinkage in the plate an example of which is shown in Figure 3. As can be seen in Table 5, the percentage reduction in maximum distortion experienced by the structure as a consequence of using alternating 
shielding gases is considerably reduced thus resulting in a flatter structure than that experienced of the constant argon base case.

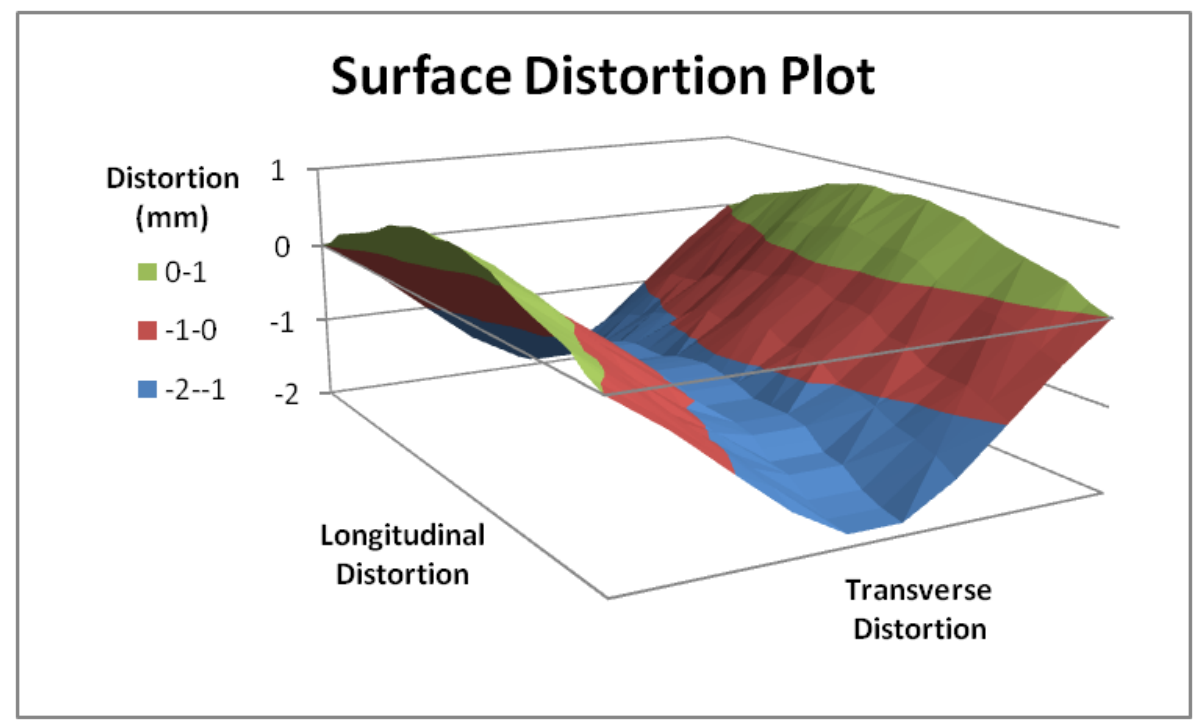

Figure 3: Typical Surface Distortion Plot

\begin{tabular}{|c|c|}
\hline Shielding Gas Configuration & Distortion Reduction (\%) \\
\hline Constant Argon & \\
\hline Alternating @ $2.5 \mathrm{~Hz}$ & 25 \\
\hline Alternating @ $5 \mathrm{~Hz}$ & 36 \\
\hline Alternating @ $7.5 \mathrm{~Hz}$ & 34 \\
\hline
\end{tabular}

Table 5: Distortion Measurements

The levels of distortion in each plate has been shown to be proportional to the amount of welding heat input. The reduced heat input for the alternating cases, as a result of the reduced welding voltage and current, therefore correlates with the reduction in distortion achieved by supplying shielding gas by the alternating method. This is a result of the alternating method taking advantage of the supply of pure helium, which produces greater penetration than argon due to its' higher first ionisation energy producing a smaller cathode spot.

\section{Thermal Data}

Thermal imaging data were collected in order to validate the data obtained through the use of thermocouples. Figures 4 and 5 show the data produced through thermal 
imaging and thermocouples respectively. The points indicated on the thermal imaging are the locations of the thermocouple and their values show good correlation to that recorded by each thermocouple.
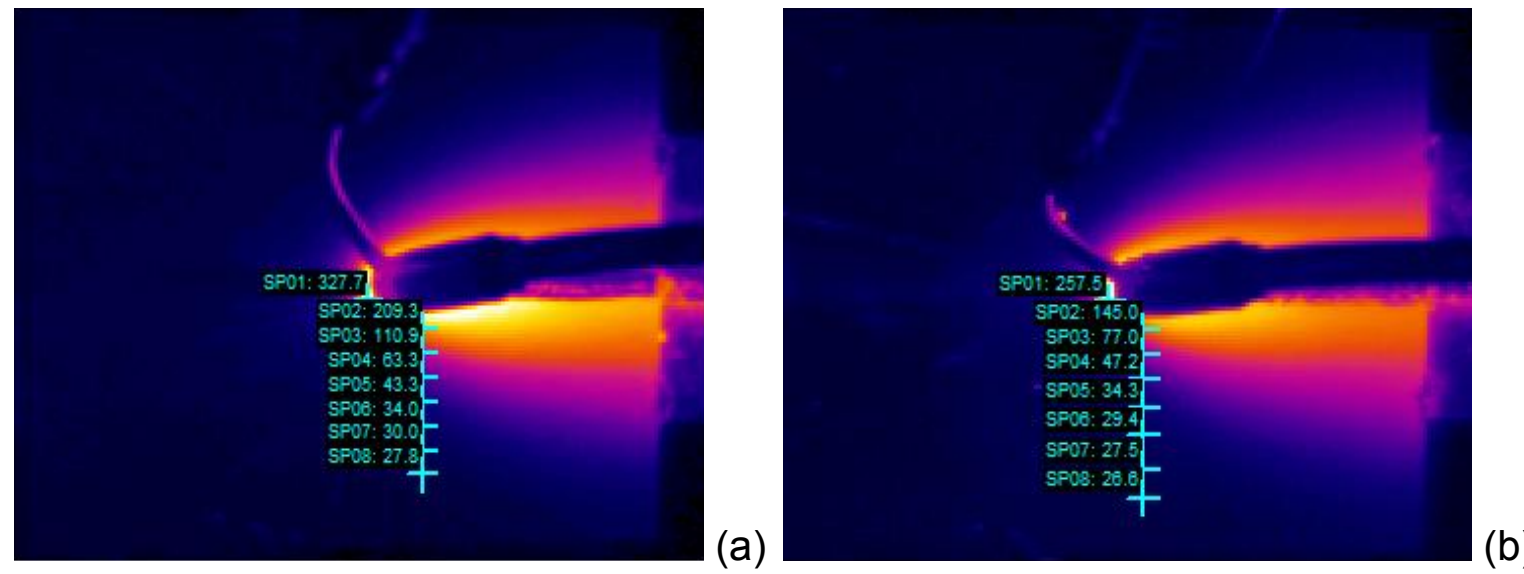

Figure 4: Thermal Imaging Data for (a) Constant Argon and (b) Alternating at $7.5 \mathrm{~Hz}$

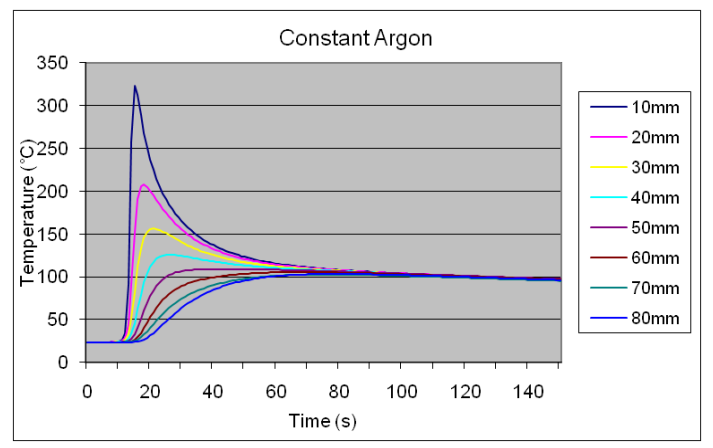

(a)

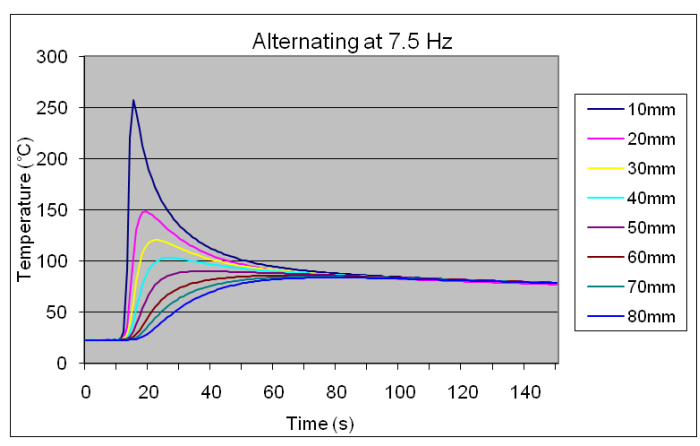

Figure 5: Thermocouple Data for (a) Constant Argon and (b) Alternating at $7.5 \mathrm{~Hz}$

The peak temperature, i.e. $10 \mathrm{~mm}$ from the weld centre line, and the temperature distribution of the alternating gas cases is shown to be considerably reduced. The peak temperature of the alternating cases were found to be approximately $70^{\circ} \mathrm{C}$ lower than that of the constant argon case. This is a result of both the reduced heat input and the narrower arc column produced by helium [12]. The results also correspond to those obtained by Campbell et al. [2] who found that the peak temperature when implementing alternating shielding gases in a steel structure was reduced. 


\section{Key Weld Geometries and Defect Level}

In order to assess any effects that the supply of alternating shielding gases have on the microstructure and heat affected zone (HAZ) of the weld, metallographic analyses were performed on a sample from each shielding gas configuration.

Helium is generally used on thicker sections of material due to its ability to increase penetration. As reported by Jönsson et al. [12] helium is generally added to gas combinations due to its ability to increase the weld depth:width ratio in comparison to constant argon. This has also been shown to be the case when implementing alternating shielding gases, even with a faster travel speed, as shown in Table 6 and depicted in Figure 6.

\begin{tabular}{|c|c|c|}
\hline Shielding Gas Configuration & Weld Width (mm) & Weld Depth (mm) \\
\hline Constant Argon & 10.5 & 5.0 \\
\hline Alternating @ $2.5 \mathrm{~Hz}$ & 10.0 & Full \\
\hline Alternating @ $5 \mathrm{~Hz}$ & 9.5 & 5.5 \\
\hline Alternating @ $7.5 \mathrm{~Hz}$ & 8.0 & Full \\
\hline
\end{tabular}

Table 6: Weld Geometry
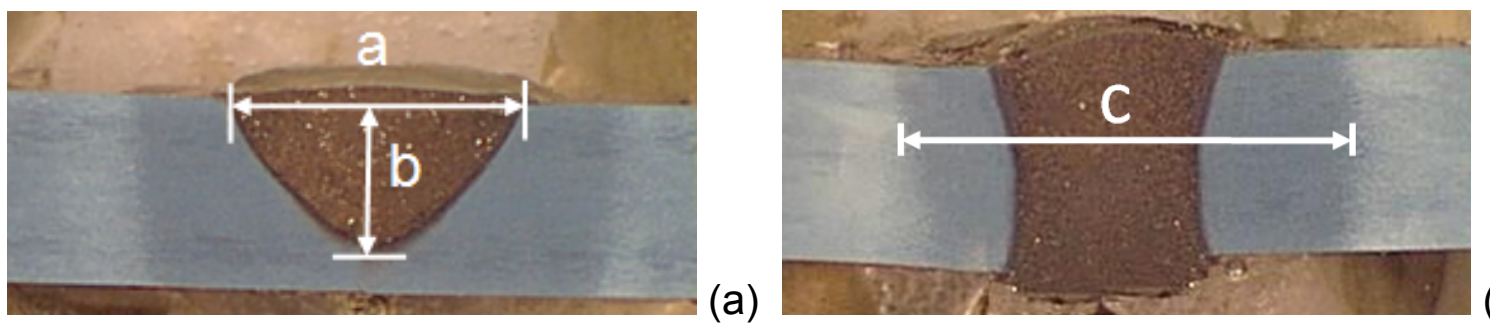

(b)

Figure 6: (a) Macrograph (Constant Argon) Showing Measurements for Weld Width and Penetration (b) Macrograph (Alternating at $7.5 \mathrm{~Hz}$ ) Showing Increased Penetration and Measurement for HAZ Width

Where:

$$
\begin{aligned}
& \text { a - Weld Width } \\
& \text { b - Weld Depth } \\
& \text { c - HAZ Width }
\end{aligned}
$$

The width of the HAZ is the area of the parent plate which had been affected by the weld heat input. The width of the HAZ, Table 7, is shown to be reduced in the case of alternating shielding gases. This is, in part, due to the reduced heat input, as a 
result of the increased travel speeds permitted, but also a consequence of the more constricted arc column of helium which had been reported by Jönsson et al. [12]. Moreover, it has been shown that increasing the frequency of alternation further reduces the HAZ width, primarily linked to the increased travel speed.

\begin{tabular}{|c|c|}
\hline Shielding Gas Configuration & HAZ Width (mm) \\
\hline Constant Argon & 15.0 \\
\hline Alternating @ 2.5 Hz & 14.0 \\
\hline Alternating @ 5 Hz & 13.5 \\
\hline Alternating @ 7.5 Hz & 13.0 \\
\hline Table 7: HAZ Width
\end{tabular}

The percentage porosity was determined using Image-Pro Plus which analysed the micrograph images of the weld pool and calculated the percentage of the image above a specified shade. Examples of the analysed images are shown in Figure 7 and the percentage porosity for each gas configuration is shown in Table 8.
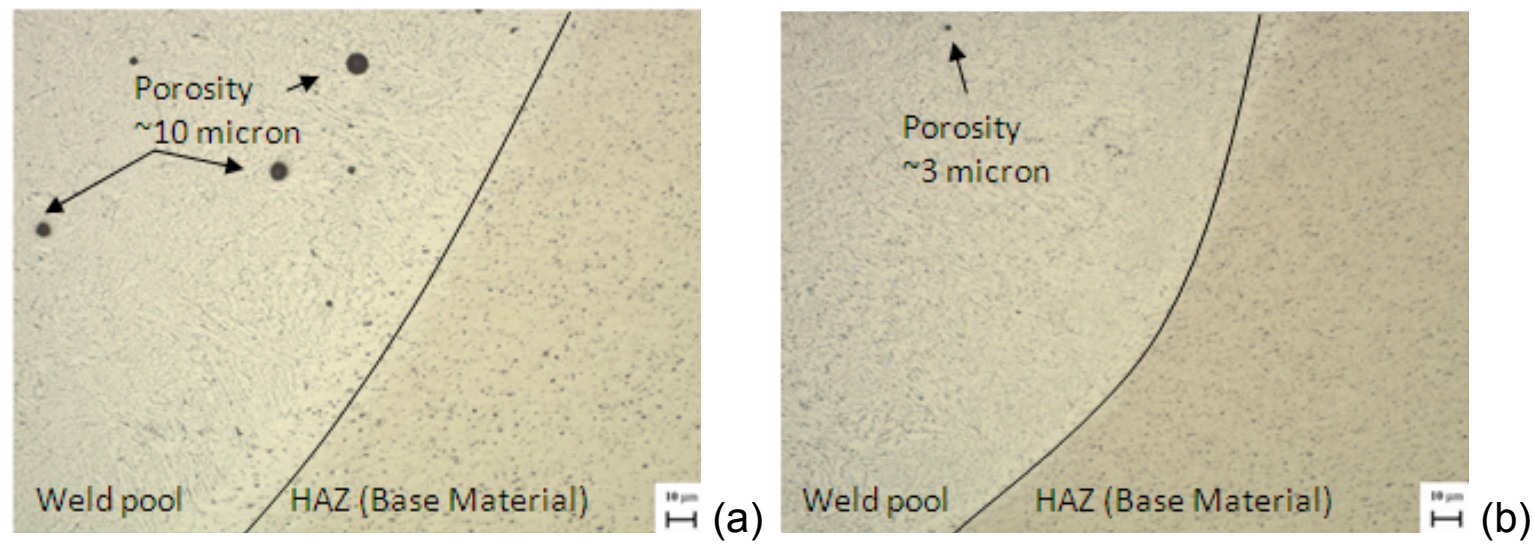

Figure 7: (a) Micrograph (Constant Argon) Showing Fusion Boundary and Porosity

(b) Micrograph (Alternating at 7.5 Hz) Showing Fusion Boundary and Reduction in Porosity

\begin{tabular}{|c|c|}
\hline Shielding Gas Configuration & Percentage Porosity (\%) \\
\hline Constant Argon & 0.5252 \\
\hline Alternating @ 2.5 Hz & 0.2484 \\
\hline Alternating @ 5 Hz & 0.1234 \\
\hline Alternating @ 7.5 Hz & 0.0926 \\
\hline
\end{tabular}

Table 8: Percentage Porosity

As can be noted, the percentage porosity is reduced through the application of alternating shielding gases, this confirms the findings of Kang et al. [4] who 
demonstrated that alternating shielding gases can reduce the porosity present in the welding of 1420 and 1460 aluminium. It was reported that this was a result of alternating shielding gases generating a dynamic action within the pool aiding the gas bubbles escape the molten weld pool. It has also been shown that increasing the frequency of alternation can further reduce the levels of porosity present within the weld.

\section{Mechanical Properties}

Transverse tensile tests were carried out, the results of which can be seen in Table 9, as anticipated all samples failed in the weld. As can be seen, the base case of constant argon produced a weld strength of approximately $85 \mathrm{MPa}$, whilst providing alternating shielding gases produced welds with strength in the region 95-110 MPa. It has been shown that the frequency of alternation also has an influence on the tensile strength of the weld, with an increased frequency resulting in an increased strength.

\begin{tabular}{|c|c|}
\hline Shielding Gas Configuration & Tensile Strength (MPa) \\
\hline Constant Argon & 84.70 \\
\hline Alternating @ 2.5 Hz & 96.45 \\
\hline Alternating @ 5 Hz & 99.42 \\
\hline Alternating @ 7.5 Hz & 110.37 \\
\hline
\end{tabular}

The tensile strength of the weld is shown to follow the same trend as the percentage porosity in that an increasing frequency of alternation produced less porosity and consequently increased the tensile strength of the weld.

In a previous study using alternating shielding gases whilst welding steel [2], it was found that a finer grain structure was generated as a consequence of accelerated cooling from a higher temperature. This helped achieve an increase in mechanical 
properties and the reduction in porosity could also be partly attributed to the finer grain distribution.

Root bend tests were carried out to ensure that no negative effects were associated with the application of alternating shielding gases.

\section{Conclusions}

The main benefits associated with alternating shielding gases is the increase in travel speed and the reduction in distortion. This is recognised to be due to the increased first ionisation energy of helium permitting faster travel speed whilst maintaining penetration. The reduction in distortion is a consequence of the reduced heat input, and narrower arc column produced by helium resulting in a narrower HAZ.

Although no economic evaluation was completed, a previous study [2] performed a comprehensive analysis for the application alternating shielding gases on DH36 steel which showed a $17 \%$ reduction in cost as a result of the reduction in manhours required.

It has been shown that, in the case of AA6082T6, the application of alternating shielding gases can reduce the level of porosity present within the weld. This is mainly attributed to the dynamic action that the weld pool experiences due to the fluctuation between different shielding gas environments.

It has also been shown that the frequency of alternation can have a pronounced affect on the mechanical properties of the weld, with an increase from $2.5 \mathrm{~Hz}$ to 7.5 $\mathrm{Hz}$ resulting in approximately $15 \mathrm{MPa}$ increase in tensile strength. However, no detrimental effects were found when subjected to bend testing. 
It is therefore considered that the application of alternating shielding gases in the GMAW process is highly suited to the welding of AA6082T6 components and offers the manufacturing community a clear benefit in terms of increased productivity, reduced porosity, moderate strength increase and a reduction in post-weld straightening.

\section{References}

1. Campbell. S.W., Galloway. A.M., McPherson. N.A. Artificial Neural Network Prediction of Weld Geometry Performed Using GMAW with Alternating Shielding Gases. Welding Journal, Under Review.

2. Campbell. S.W., Galloway. A.M., McPherson. N.A. Techno-Economic Evaluation on the Effects of Alternating Shielding Gases for Advanced Joining Processes. Proceedings of IMechE Part B: Journal of Engineering Manufacture, In Press.

3. Chang, Y. H. 2006. Improve GMAW and GTAW with Alternating Shield Gases. Welding Journal, 85(2): p41-43.

4. Kang, B.Y., Prasad, Y.K.D.V., Kang, M.J., Kim, H.J., Kim, I.S. 2009. Characteristics of Alternate Supply of Shielding Gas in Aluminium GMA Welding. Journal of Materials Processing Technology, 209: p4716-4121.

5. Kang, B.Y., Prasad, Y.K.D.V., Kang, M.J., Kim, H.J., Kim, I.S. 2009. The Effect of Alternate Supply of Shielding Gases in Austenite Stainless Steel GTA Welding. Journal of Materials Processing Technology, 209: p4722-4127.

6. Marya, M., Edwards, G. R., and Liu, S. 2004. An Investigation on the Effects of Gases in GTA Welding of a Wrought AZ80 Magnesium Alloy. Welding Journal, 83(7): p203-212. 
7. Tani, G., Campana, G., Fortunato, A., Ascari, A. 2007. The Influence of Shielding Gas in Hybrid Laser-MIG Welding. Applied Surface Science, 253: p8050-8053.

8. Galloway, A.M., McPherson, N.A., Baker, T.N. 2011. An Evaluation of Weld Metal Nitrogen Retention and Properties in 316LN Austenitic Stainless Steel. Journal of Materials: Design and Applications, 225(2), pp. 61-69.

9. Gillies, A., Galloway, A.M., McPherson, N.A. Helium Additions to MIG Shielding Gas - An Economic Option? Welding and Cutting, 10(2), pp. 118-121.

10. Jeffus, L. F. 2002. Welding: principles and applications, Fifth Edition, pp. 253255 (Cengage Learning, USA).

11. Welding and brazing: ASM metals handbook, Eighth Edition, Vol. 6, p.85 (ASM, Metals Park Ohio).

12. Jönsson, P.G., Eagar, T.W., Szekely, J. 1995. Heat and Metal Transfer in Gas Metal Arc Welding Using Argon and Helium. Metallurgical and Materials Transactions B, 26B p383-395.

13.Polmear, I. 2006. Light Alloys: From Traditional Alloys to Nanocrystals, Fourth Edition, pp. 170-184 (Elsevier Ltd., UK).

14. Deng, D., Murakawa, H. Prediction of Welding Distortion and Residual Stress in a Thin Plate Butt-Welded Joint. Computational Materials Science, 2008, 43(2008): p353-365.

15. Hong, L., Ren, H. Simulation of Welding Deformations of Ship Structures. Key Engineering Materials, 2006,324-325: p651-654.

16.Lightfoot, M.P., Bruce, G.J., McPherson, N.A., Woods, K. 2005. The Application of Artificial Neural Networks to Weld-Induced Deformation in Ship Plate. Supplement to the Welding Journal, p23-26. 
17.Lightfoot, M.P., McPherson, N.A., Woods, K., Bruce, G.J. 2006. Artificial Neural Networks as an Aid to Steel Plate Distortion Reduction. Journal of Materials Processing Technology, 172: p238-242.

18. Min, D., Shen, J., Lai. S., Shen. J. Effect of Heat Input on the Microstructure and Mechanical Properties of Tungsten Inert Gas Arc Butt-Welded AZ61 Magnesium Alloy Plates. Materials Characterization, 2009, 60(2009): p1583-1590. 